\title{
Inclusão dos idosos no meio digital com educação em saúde: projeto piloto
}

\author{
Samir Antonio Rodrigues Abjaude \\ samirabjaude@hotmail.com \\ Tayra Ferreira Oliveira de Lima \\ tayraferreira@yahoo.com.br \\ Nicole Rodrigues da Silva \\ nikarodrigues963@hotmail.com \\ Luciene Alves Moreira Marques \\ lualvesmarques@gmail.com \\ Ricardo Radighieri Rascado \\ ricardounifal@gmail.com
}

\section{Resumo}

O Brasil está passando por uma modificação na faixa etária populacional com o aumento do número de idosos, os quais possuem tendência de perdas cognitivas de memória e maior uso de medicamentos. Assim, o projeto UNAFAL teve como proposta o desenvolvimento de ações educativas em saúde na inclusão digital para formar idosos mais esclarecidos quanto ao uso racional de medicamentos e com acesso à informação em saúde. Além disso, formar o acadêmico para orientação farmacêutica e educação em saúde. Foram produzidos setes materiais educativos para trabalhar juntamente com ferramentas da informática destinados a idosos, no período de maio a novembro de 2012, e foi criado um questionário para avaliar o período anterior e posterior da intervenção do projeto. As palestras apresentaram um rendimento positivo, alcançando o aproveitamento final de 78,92\% na análise dos questionários dos idosos. Já para os acadêmicos, o projeto elevou a didática de ensino e contribuiu para promoção de saúde. Desse modo, o estudo objetivou que o acesso digital aumentaria as informações e poderia colaborar com o tratamento dos participantes, e os acadêmicos observaram que pequenas ações podem contribuir para a construção de uma sociedade mais preparada para enfrentar criticamente as informações vinculadas aos medicamentos.

Palavras-chave: Educação em saúde. Uso racional de medicamento. Conhecimentos em informática. 


\section{Inclusion of elderly in the middle with digital health edu- cation: pilot project}

\section{Abastract}

The Brazil is going through a change in the age group population with increasing numbers of elderly people, and these tend to have cognitive losses in memory and greater use of medicines. Objective: So the project was to UNAFAL proposed the development of educational digital inclusion in health in elderly to form more enlightened as to the rational use of medicines and access to health information. Additionally, form the academic guidance to pharmaceutical and health education. Method: Production of sevens educational materials to work together with informatics tools for the elderly in the period May-November 2012. Creating a questionnaire to assess the period before and after the intervention of the project. Result: The lectures presented a positive income, reaching $78.92 \%$ of end use analysis of questionnaires in the elderly. As for academics, the project raised the didactic teaching and contributed to health promotion. Conclusion: Thus the study aimed to increase access to digital information and could help with the treatment of the participants, and academics observed that small actions can contribute to building a more prepared to confront critically the information linked to medicines.

Keywords: Health education. Rational drug use. Computer literacy.

\section{INTRODUÇÃO}

Na última década no Brasil, os idosos representavam 10,8\% da população (20 milhões de idosos) (IBGE, 2010a). Segundo Baldoni e Pereira (2011), caso as projeções se confirmem no ano de 2050, eles representarão aproximadamente $30 \%$ da população do Brasil. Assim, a população brasileira exibirá uma pirâmide populacional semelhante às atuais situações dos países da Europa, e consequentemente o Brasil talvez seja um dos países mais populosos de idosos no mundo (CARVALHO, GARCIA, 2003; IBGE, 2008 apud BALDONI; PEREIRA, 2011).

Porém, o que mais impacta nesse cenário, entre os anos de 2002 a 2006, foi o crescimento financeiro de 123,9\% destinado à compra de medicamentos no país, ao mesmo tempo que o capital do Ministério da Saúde elevou 9,6\% (VIEIRA, MENDES, 2007 apud BALDONI, PEREIRA, 2011). A partir desses dados e considerando que a faixa de idosos representa a categoria que mais utiliza medicamentos, é clara a necessidade de prática do uso racional de medicamentos para adequar esses recursos terapêuticos disponíveis (BALDONI, PEREIRA, 2011).

Também em relação à faixa etária da terceira idade, ela convive com mais frequência com falhas cognitivas nesse período de vida. Assim, para diminuir tal perda de memória, é fundamental o aumento de estímulos com atividades, para conservar a memória em operação, mesmo que haja diferenças genéticas para compreender cada individuo (ALMEIDA et al., 2007, SOUZA e CHAVES, 2005 apud OLIVEIRA et al., 2012).

Segundo Bizelli e colaboradores (2009), a informática é uma ferramenta para inclusão digital da terceira idade e uma atividade que ajuda a conservar a memória, estimula a socialização e põe o idoso em contato com o mundo moderno. Ademais, as fontes tecnológicas estão mais presentes na sociedade, e o computador, 
entre os bens duráveis, obteve o maior aumento no período de dez anos, de 10,6\% em 2000 para 38,3\% em 2010, dos domicílios (IBGE, 2011). Entretanto, essa tecnologia de informação associada com a internet acarretou o aumento expressivo do processo denominado "exclusão digital" para aquelas pessoas que não utilizam diariamente o computador, ou por motivos da faixa etária ou pela condição financeira. Com isso, as pesquisas confirmam que a terceira idade vem procurando muito mais o processo de informatização e conhecimentos contemporâneos (MIRANDA, FARIAS, 2009). Assim, a inclusão digital da terceira idade é uma prática que pode causar enormes benefícios para essa faixa etária (OLIVEIRA, 2006; BIZELLI et al., 2009 apud DOTTA et al., 2012).

Atualmente, os idosos têm buscado se inscrever em programas destinados a sua faixa etária, como, por exemplo, o programa da Universidade Aberta à Terceira Idade ( UNATI), promovido desde 1999, por meio da Pró-Reitoria de Extensão da Universidade Federal de Alfenas-MG ( UNIFAL-MG), campus Alfenas, com a finalidade de contribuir para melhoria da qualidade de vida das pessoas da terceira idade proporcionando orientação e serviços de saúde específicos, cursos de capacitação e oportunidades de lazer. Uma das atividades oferecidas pela UNATI, semestralmente, é o curso presencial de Informática.

Dessa forma, foi criado em 2012 o projeto de extensão UNAFAL, através do programa Centro de Farmacovigilância da UNIFAL-MG (CEFAL), que visou trabalhar a temática educação em saúde com os idosos da UNATI, uma vez que Marques e colaboradores (2010) apontaram que $88 \%$ dos idosos da UNATI utilizam medicamentos, e 18\% utilizam polifarmácia, administrando seis ou mais medicamentos. Nesse contexto, ainda considerando o elevado crescimento dessa faixa etária e o fato de que os idosos lidam mais com enfermidades degenerativas e crônicas, eles geralmente usam mais medicamentos em relação à população mais jovem, podendo resultar em mais eventos adversos e interações medicamentosas (MARQUES et al., 2010). Portanto, o projeto UNAFAL foi incluído dentro da atividade informática, na qual trabalhou a inclusão digital e o uso racional de medicamento igualmente, a fim de estimular o acadêmico de Farmácia a promover o acesso às informações em saúde, podendo colaborar com o tratamento dos participantes, contribuindo para a construção de uma sociedade mais preparada para enfrentar criticamente as informações vinculadas aos medicamentos e sua própria saúde.

Diante da problemática do aumento da faixa etária e consequentemente da elevada incidência do uso de medicamentos e a busca por práticas de estímulos à memória, este estudo apresentou como objetivo conscientizar os alunos da terceira idade sobre o uso racional de medicamentos, estimular a utilização das ferramentas da informática para acesso às boas práticas em saúde e fornecer ao acadêmico de Farmácia a prática de educação em saúde, além de avaliar o alcance das práticas desenvolvidas no projeto piloto através do rendimento dos participantes.

\section{Material e Métodos}

O projeto foi desenvolvido na cidade de Alfenas-MG, localizada a $344 \mathrm{~km}$ de distância da capital de Minas Gerais, e composta por 73.774 habitantes, sendo 36.081 homens e 37.693 mulheres, dos quais 9.051 são idosos ( $\geq 60$ anos) (IBGE, 2010b). Iniciou-se em maio de $2012 \mathrm{e}$, em sua primeira fase, contemplaramse a aprovação do projeto pela Pró-Reitoria de Extensão da UNIFAL-MG e aceitação da participação do projeto UNAFAL dentro da atividade de informática da UNATI.

Nesse primeiro momento, houve uma reunião com os seis acadêmicos do curso de Farmácia da Faculdade de Ciências Farmacêuticas participantes do projeto para esclarecer os objetivos deste e tornálos cientes das ações a serem desenvolvidas. No primeiro semestre, foram acompanhadas duas aulas para observar o público-alvo e analisar as ferramentas utilizadas na aula de informática. Também foram definidos datas, horários e programação das atividades e escolha dos temas ligados à saúde para fazerem parte do programa educativo. A partir disso, foram produzidos os setes materiais educativos como: uso racional de medicamentos, armazenamento de medicamentos, descarte de medicamentos, medicamentos falsificados, 
alimentação saudável, diabetes e hipertensão. Esses temas foram baseados nos materiais do EDUCANVISA da Agência Nacional de Vigilância Sanitária (ANVISA) e em outros materiais relacionados à promoção da saúde. O material do EDUCANVISA foi destinado para estimular a mudança de hábitos e atitudes prejudiciais à saúde de alunos do ensino fundamental. No entanto, o projeto piloto UNAFAL extrapolou os conhecimentos e direcionou para atender o público da terceira idade. Esse projeto piloto também visou criar uma atividade de avaliação, a fim de analisar o período anterior (H0) e depois da intervenção do projeto (H1). Dessa forma, o trabalho pode avaliar o impacto e melhorar o conteúdo e a metodologia do próximo ano. $\mathrm{O}$ questionário (figuras 1 e 2) continha 12 questões objetivas de marcar e enumerar, sendo duas questões de diabetes, duas de hipertensão, duas de alimentação saudável, uma de uso racional de medicamento, uma de diferença de conceito de medicamento $\mathrm{x}$ remédio, uma de armazenamento, uma de descarte, uma de identificação de embalagem verdadeira de medicamento e a última de medicamento falso. Esse questionário de avaliação foi adaptado para o público-alvo, baseado no material do EDUCANVISA e no questionário validado do projeto EDUCEFAL pertencente ao mesmo programa CEFAL (ABJAUDE et al., 2012; BRASIL, 2007).

O delineamento amostral não foi probabilístico, e sim por conveniência, sendo a população estudada representada por $\mathrm{n}=11$, uma vez que o curso de informática abre poucas vagas, devido à natureza desse curso requerer um acompanhamento mais individual e personalizado dos alunos, semelhante a outro curso de informática descrito por Oliveira et al. (2012). Assim, o instrutor do curso precisa estar bem atento principalmente nas primeiras aulas e muitas vezes precisa auxiliar alguns alunos ajudando-os a manusearem o equipamento, como também descrito em outro curso por Bizelli et al. (2009). No entanto, duas pessoas se recusaram a assinar o termo de consentimento livre e esclarecido (TCLE) oferecido pelos acadêmicos antes do questionário de avaliação.

Figura 1: Primeira parte do questionário

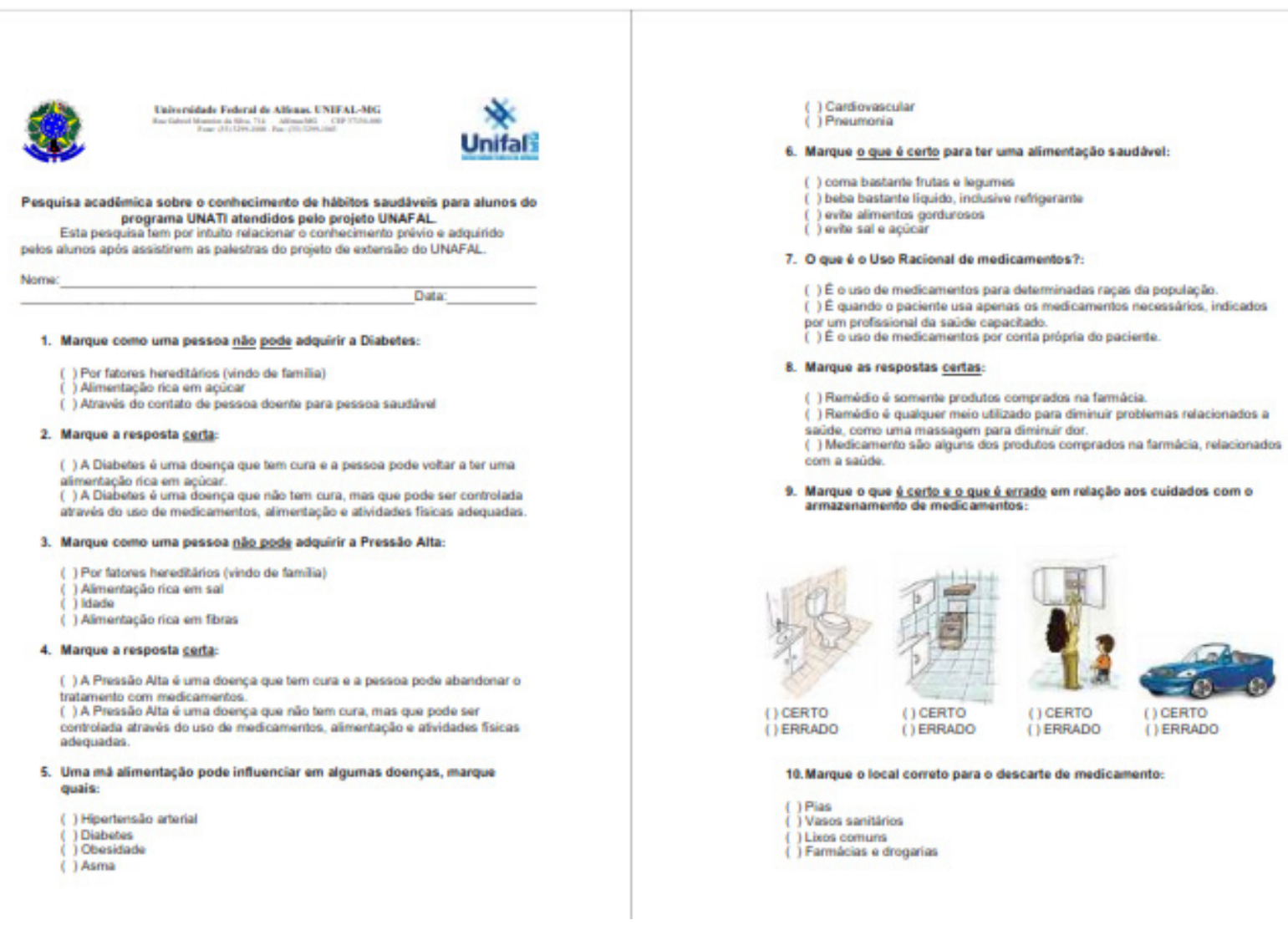

Fonte: Adaptada de Abjaude et al. (2012) e Brasil (2007) 
No segundo semestre, iniciou-se a capacitação dos participantes com a apresentação das temáticas e exposição de atividades relacionadas, sendo tais participantes responsabilizados pela aplicação dos temas que seriam ministrados uma vez por semana durante uma hora. Assim, antes de se iniciar qualquer contato da equipe do UNAFAL com os alunos da terceira idade, foi oferecido inicialmente o TCLE para os alunos e, após consentimento, foi aplicado o questionário uma semana antes de se iniciarem as atividades, com a finalidade de verificar o conhecimento prévio desses alunos e servir como comparação para analisar o impacto do projeto. Esse questionário foi distribuído para todos os nove participantes, e foi feita uma orientação do objetivo do questionário, solucionado algumas dúvidas de preenchimento. Os participantes tiveram no máximo 20 minutos para respondê-lo, sem consulta aos acadêmicos e ao computador.

Figura 2: Parte final do questionário

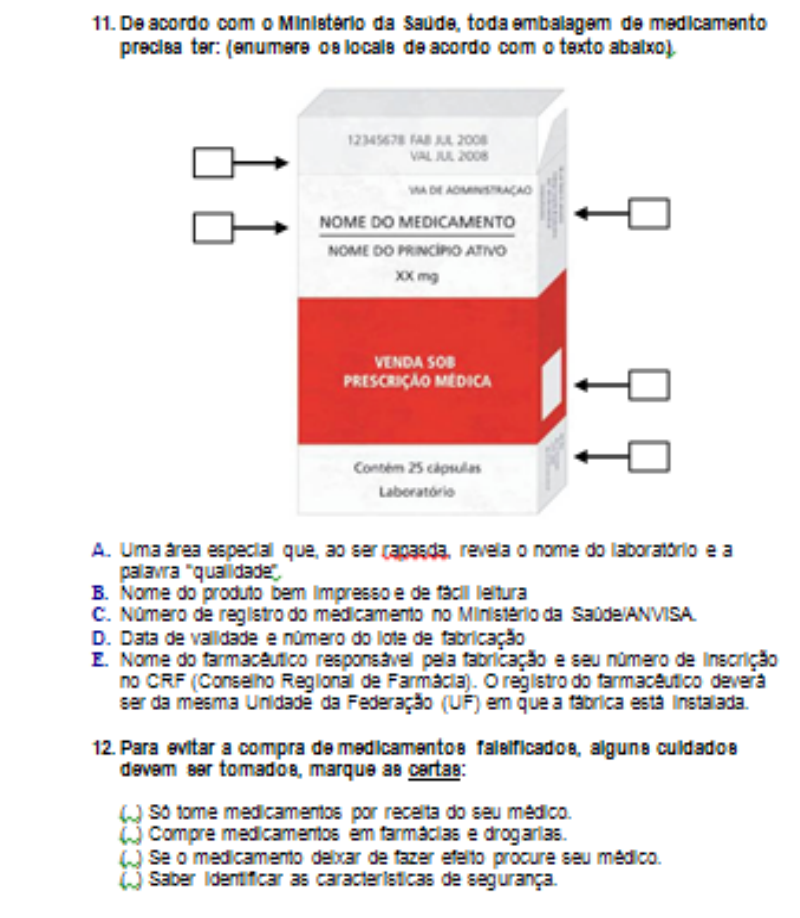

Fonte: Adaptada de Abjaude et al. (2012) e Brasil (2007)

A aula de informática ocorria com periodicidade semanal em um laboratório didático de computação da UNIFAL-MG e possuía duração de 120 minutos, sendo os 60 minutos iniciais para o professor desenvolver atividade restrita à parte técnica à informática, a fim de trabalhar a temática tecnológica com os alunos, os quais possuíam cada um um computador para o trabalho individual. Após essas atividades, os acadêmicos do projeto UNAFAL tinham 60 minutos para trabalhar atividades com temas de saúde associados à inclusão digital.

Na semana seguinte à avaliação inicial, houve a primeira apresentação, na qual foram tratadas temáticas com ferramentas da informática como uso de e-mail, sites de buscas, criação de texto em ferramentas de escritas, etc. Já os acadêmicos utilizavam tela interativa para tornar a aula mais baseada na temática de inclusão digital.

As aulas expositivas foram construídas em educação em saúde e baseadas em temáticas discutidas nas disciplinas da Faculdade de Ciências Farmacêuticas da Universidade Federal de Alfenas/MG (FCF-UNIFAL/ MG). Dessa forma, o acadêmico de Farmácia tem um dos primeiros contatos diretamente com o paciente 


\section{Extensio $\mid$ Artigo}

na discussão de assuntos relacionados à saúde e na solução de algumas dúvidas em relação ao assunto abordado. Assim, os acadêmicos precisavam sintetizar e esclarecer assuntos trabalhados nas disciplinas da graduação, para serem claros e objetivos para os pacientes. Esses acadêmicos foram subdivididos em cada aula: um apresentaria uma temática e os demais seriam monitores para os idosos para instrução no uso das ferramentas de informática.

Durante os sete dias de atividades, foi realizada uma lista de presença, a fim de se analisarem o aproveitamento do aluno e sua frequência na disciplina, e, uma semana após se encerrarem as atividades do projeto, foi aplicado o mesmo questionário com a condição igual a da primeira avaliação, no entanto, no tempo final, para que se pudessem avaliar o aprendizado do aluno e o impacto do projeto, para estabelecer novas metas para um próximo ano.

Para correção das questões, foi utilizado o seguinte critério: de zero a um ponto para cada questão, totalizando 12 pontos indicando $100 \%$ de aproveitamento. Pelo fato de as questões cinco, seis, oito e 12 apresentarem mais de uma alternativa correta em uma mesma questão, foi divido igualmente o valor total (um ponto) de uma questão para cada alternativa correta em uma mesma questão. Além disso, foi estabelecido que, para cada alternativa errada, seria descontada a metade de uma alternativa certa na mesma questão, para penalizar o erro, uma vez que isso foi mais justo para aquele aluno que acertou uma alternativa e errou outra, para diferir do aluno que não marcou nenhuma alternativa. Esses questionários foram corrigidos por dois acadêmicos, a fim de se ter segurança nos resultados.

O projeto UNAFAL é incluído no programa CEFAL e foi jugulado no Comitê de Ética em Pesquisa da Universidade Federal de Alfenas, tendo sua aprovação em 5 de maio de 2011 com o protocolo 075/2011. Esse projeto foi aprovado de maio a dezembro de 2012 pela Pró-Reitoria de Extensão da UNIFAL-MG e foi executado após o acordo com o coordenador da UNATI autorizando as atividades do projeto concomitantemente com o curso de informática.

\section{RESULTADOS E ANÁLISE}

A turma do curso de informática e abrangida pelo projeto UNAFAL era composta de nove alunos, sendo seis mulheres e três homens, com idade média de 61 anos (57-73 anos), com escolaridade entre ensino fundamental até superior completo. Três participantes cursaram até o ensino fundamental, dois até o ensino médio e quatro cursaram o ensino superior, tendo uma farmacêutica. O quadro clínico desses participantes era composto por três participantes sem nenhum problema de saúde relatado; quatro com hipertensão, sendo um idoso com colesterol alto associado; dois possuíam problemas na coluna, no entanto, um deles possui também fibromialgia, desgaste ósseo, bursite, tendinite, artrite, artrose e depressão.

Houve a aplicação do questionário de autoavaliação em dois momentos distintos, $\mathrm{H} 0$ e H1, e, dessa forma, pode-se comparar as médias dos dados de cada questão da turma (Figura 3), revelando a evolução do aprendizado dos participantes, e, de uma forma geral, o projeto obteve um aumento do rendimento dos questionários.

Esse resultado pode ter sido influenciado também pelo modo de ministrar as temáticas de uma forma leve e descontraída, buscando que os acadêmicos se enturmassem com os participantes e tivessem total paciência na explicação, o que reforça a assertiva de Bizelli et al. (2009).

A primeira questão e a segunda questão (Figura 1) foram produzidas para associar a condição clínica do quadro de diabetes relatado na palestra. Assim, a intenção foi, no mínimo, que os participantes soubessem como adquirir a diabetes e a condição de vida e tratamento para um diabético. Dessa forma, as duas questões iniciais foram de marcar a alternativa de acordo com a pergunta da questão. Nessa primeira questão, houve pouca diferença no rendimento, e, na segunda pergunta, não houve mudança, sendo total o aproveitamento da questão. Isso demonstra o conhecimento de quadro clínico pelos participantes e um total aproveitamento dessa palestra.

A duas próximas questões, número três e quatro, foram construídas com o mesmo objetivo das anteriores; no entanto, abordavam a hipertensão. Na terceira questão, percebeu-se um baixo rendimento em H0 e um pequeno 
aumento no H1. Esperava-se que houvesse $100 \%$ de acertos no mínimo; entretanto, dos quatro participantes em que essa patologia é incidente, um deles errou essa questão, demonstrando que o projeto ainda precisa enfatizar mais essa problemática e aprofundar o assunto. Já na quarta questão, não houve diferença quanto ao mesmo questionamento da primeira e segunda questão, embora os participantes não tenham tido total aproveitamento desse assunto, devido ao resultado da questão três.

As questões cinco e seis foram construídas para serem marcadas mais de uma alternativa, sendo os objetivos das questões associar a influência da alimentação saudável às patologias diversas e conhecer as atitudes correspondentes para se ter uma alimentação saudável. Essas questões tiveram um resultado inferior ao esperado entre $\mathrm{HO}$ e $\mathrm{H} 1$, talvez pelo fato das faltas cometidas pelos quatro dos cinco participantes, que responderam ao questionário em $\mathrm{H} 1$, o que influenciou diretamente no aproveitamento das palestras.

Durante o tempo de atuação do projeto, houve também a elaboração de uma lista de presença para acompanhar a avaliação e correlacioná-la com a participação. Os acadêmicos perceberam que apenas dois participantes presenciaram todas as sete palestras, dois faltaram a cinco das sete palestras e não houve desistência. Neste estudo, observou-se que os idosos mais participativos no projeto obtiveram maiores rendimentos. Essa falta dos idosos nas aulas é inevitável e já esperado pelo projeto, também discutido por Bizelli et al. (2009). Ela prejudicou a avaliação dos nove participantes no momento $\mathrm{H} 0$ e H1, e suas causas foram: problemas de saúde, viagem inadiável e até mesmo mudança climática.

A questão número sete abordava o conceito básico sobre uso racional de medicamento, que é a temática principal deste projeto. Esse assunto foi amplamente discutido nas palestras, e pode-se observar o total aproveitamento nessa questão nos dois momentos avaliados.

A próxima questão, número oito, foi elaborada para diferenciar o conceito de medicamento $\mathrm{x}$ remédio e foi construída para serem assinaladas mais de uma alternativa correta. A maior parte dos participantes marcou apenas uma alternativa das duas corretas. Assim, o aproveitamento final em $\mathrm{H} 1$ não foi o esperado pela equipe. Esse conceito em uma próxima oportunidade deve ser mais amplamente trabalhado abordando mais exemplos.

As últimas quatro questões tratavam de práticas sobre o reconhecimento e manejo do medicamento, que são temas importantes para todas as faixas, principalmente para a terceira idade, que tem tendência a usar um grande número de medicamentos. Essas questões apresentaram resultados satisfatórios.

A questão nove solicitava que fossem assinalados os locais certos e errados para o cuidado do armazenamento do medicamento, sendo o local adequado para armazenamento um armário alto, fora do alcance de crianças; já os locais inadequados foram cozinha, banheiro e carro, devido à umidade e temperatura excessiva, que estão fora das condições ideais de conservação. Esse tema é de grande importância, devido ao costume comum de armazenar medicamentos em locais inadequados. O armazenamento correto, para segurança e qualidade do medicamento, é indispensável para assegurar a estabilidade físico-química, microbiológica e terapêutica para manter a eficácia do produto (LIMA et al., 2007 apud PINTO et al., 2011).

A temática do descarte de medicamento, elaborada na questão seguinte, trouxe uma discussão sobre o destino final das preparações farmacêuticas. Assim, na palestra abordou-se que o único local correto para o descarte de qualquer medicamento é apenas nas farmácia e drogarias, pois elas possuem um Plano de Gerenciamento de Resíduos de Serviços de Saúde para descartar as sobras e materiais vencidos. Nessa oportunidade, também foi divulgado o serviço Descarte Consciente de Medicamentos, promovido pela farmácia universitária da UNIFALMG, que oferece para qualquer pessoa o serviço de descarte de resíduos de medicamentos utilizados em casa.

A décima primeira questão foi elaborada com o objetivo de se reconhecer um medicamento verdadeiro e solicitava que se associasse a caixa de medicamento com as letras que indicavam os espaços, como o nome do medicamento; selo de qualidade; número do registro do medicamento no Ministério da Saúde/ANVISA; data de validade e número do lote de fabricação; nome do farmacêutico responsável pela fabricação e seu número de inscrição no Conselho Regional de Farmácia.

$\mathrm{Na}$ última questão, a qual tratou da temática dos cuidados para se evitar um medicamento falsificado, não houve praticamente diferença no $\mathrm{H} 0$ e H1. Foi observado que esse assunto deve ser mais elaborado em um segundo momento de atividade. Até mesmo porque essa temática é de grande importância para as pessoas que possuem 
pouco controle com o contato com medicamentos inapropriados. Semelhante quando ocorrem as prescrições indevidas ou quando medicamentos com suspeita na eficácia, qualidade e segurança, como os medicamentos falsos, são comercializados (LUCHESSI et al., 2005 apud PINTO et al., 2011).

No entanto, como se observou que participantes da terceira idade provavelmente possuem amplo conhecimento, devido às diferentes experiências de vida, houve a intenção de avaliar o antes eo depois da intervenção do projeto. Assim, as questões abordadas no questionário foram construídas para se avaliar o conhecimento desejável de cada assunto aplicado nas palestras. Dessa forma, encontrou-se um aumento do rendimento médio da turma no questionário entre $\mathrm{H} 0$ e $\mathrm{H1}$; porém, observou-se que não houve aumento do rendimento médio em algumas questões, provavelmente porque elas foram abordadas com tópicos simples e/ou porque as palestras não aprofundaram o assunto, abordando apenas o conhecimento prévio desses participantes. O projeto também foi ao encontro da discussão de Pinto et al. (2011), o que deixa claro que as ações do projeto não podem apenas repassar informações de conceitos a serem aceitas com ausência de uma discussão. De tal modo, o projeto observou que, em um próximo momento da realização do UNAFAL, precisará aprofundar mais os conhecimentos repassados nas palestras e construir perguntas mais específicas, demonstrando o assunto e técnicas inovadoras do momento, uma vez que esses participantes são pessoas interessadas em conhecimento e possuem acesso a meios de informação, entre os quais a internet.

Figura 3: Rendimento médio e valores mínimos e máximos de cada questão correspondente ao questionário no período anterior $(\mathrm{H} 0)$ e depois da intervenção do projeto $(\mathrm{H} 1)$

\begin{tabular}{|c|c|c|}
\hline QUESTÃO & HO & H1 \\
\hline & $83,33 \% \quad(0-100 \%)$ & $100 \% \quad(100 \%)$ \\
\hline & $100 \% \quad(100 \%)$ & $100 \% \quad(100 \%)$ \\
\hline & $50 \% \quad(0-100 \%)$ & $60 \% \quad(0-100 \%)$ \\
\hline & $100 \% \quad(100 \%)$ & $100 \% \quad(100 \%)$ \\
\hline & $77,16 \% \quad(25-100 \%)$ & $65 \% \quad(0-100 \%)$ \\
\hline & $74,16 \% \quad(35-100 \%)$ & $60,20 \% \quad(18-100 \%)$ \\
\hline & $100 \% \quad(100 \%)$ & $100 \% \quad(100 \%)$ \\
\hline & $50 \% \quad(0-100 \%)$ & $55 \% \quad(0-100 \%)$ \\
\hline & $83,33 \% \quad(0-100 \%)$ & $95 \% \quad(75-100 \%)$ \\
\hline & $66,67 \% \quad(0-100 \%)$ & $80 \% \quad(0-100 \%)$ \\
\hline & $40 \% \quad(0-60 \%)$ & $72 \% \quad(20-100 \%)$ \\
\hline & $59,16 \% \quad(18-83 \%)$ & $60,04 \% \quad(0-83 \%)$ \\
\hline $\begin{array}{c}\text { RENDIMENTO } \\
\text { MÉDIO }\end{array}$ & $70,59 \%$ & $78,92 \%$ \\
\hline
\end{tabular}

Fonte: Elaborada pelos autores 
O fator limitante da pesquisa, que o projeto não conseguiu avaliar, foi a diferença entre acadêmicos que ministravam as disciplinas: um poderia ser mais didático do que outros, podendo influenciar no rendimento dos alunos. Isso foi diminuído pela ajuda dos outros acadêmicos que foram monitores dos idosos, que também recorriam a eles para dirimir dúvidas. Além disso, este projeto também objetivou ser o primeiro contato da discussão da educação em saúde entre os acadêmicos com os idosos. Dessa forma, o projeto proporcionou chances iguais para os acadêmicos ministrarem as aulas.

Mesmo sendo um projeto piloto que pretendeu analisar os tópicos positivos, melhorar as limitações, validar a metodologia, o UNAFAL se viu importante para a contribuição da universidade com a comunidade, destacando a importância de atividades educativas que contribuam para o uso racional de medicamento e promoção da saúde para população (ARRAIS et al., 1997; SHENKEL et al., 2005; NETO et al., 2006 apud PINTO et al., 2011).

Em relação aos acadêmicos de Farmácia que participaram do projeto - que tiveram a oportunidade de estar mais próximos dos pacientes e de seus problemas, tanto de saúde quanto de interação com a informação das redes sociais -, não houve uma ferramenta quantitativa para avaliação sistematizada do impacto; porém, ela se deu em razão da importância e da satisfação dos participantes. Nessa oportunidade, os acadêmicos foram treinados para desenvolverem educação em saúde, puderam prestar uma orientação farmacêutica para os idosos, além de compartilharem experiências, que colaboram com o conhecimento científico, cultural e crescimento pessoal dos acadêmicos. Algo semelhante foi demonstrado por Marques et al. (2010) e Plucenio et al. (2010). Foi observado e relatado também por Bizelli et al. (2009) que esse contato com métodos didáticos pode ser um acontecimento importante para um futuro professor.

Considerações Finais

O fato de o projeto UNAFAL abranger o objetivo de abordar temas de saúde juntamente com a inclusão digital e de Miranda e Farias (2009) demonstrarem, através de estudos de revisão, que a internet é um instrumento eficiente na divulgação de informações sobre saúde para idosos, mostra que se podem relacionar as temáticas do projeto juntamente com o aprendizado da tecnologia digital, estimulando, assim, a memória dos idosos com conhecimentos mais atrativos que fazem parte da sua vivência. Essa prática, pelo seu alcance e interação, segundo Miranda e Farias (2009), é ainda mais útil quando associada às políticas de saúde pública.

Embora o rendimento médio dos questionários apresentasse uma pequena diferença relativa de impacto, mesmo assim ele foi positivo. Essa análise servirá como referência para traçar novas metas, novos temas e uma modificação na metodologia para continuidade do projeto esperando mais impacto positivo em um próximo ano.

No entanto, o projeto foi de grande importância para a didática de ensino e discussão dos acadêmicos de Farmácia, uma vez que esse desafio os deixou diante dos questionamentos dos pacientes sobre doenças e medicamentos. Dessa forma, transformou os acadêmicos em profissionais mais instruídos sobre orientação farmacêutica e educação em saúde. Essa mesma discussão pode ser vista também no projeto EDUCEFAL, o qual aborda o aprendizado dos acadêmicos para discussão de temas de saúde; no entanto, para alunos do ensino fundamental na sala de aula; e aborda a percepção dos acadêmicos em utilizar um vocabulário fácil e claro para tratar do uso racional de medicamentos e promoção da saúde (ABJAUDE et al., 2012).

Essa proposta de interdisciplinaridade pode servir de modelo e estímulo para outras temáticas serem trabalhadas conjuntamente para um melhor aproveitamento, considerando que a educação é uma importante tática, como corrobora Plucenio et al. (2010), para o cuidado e a promoção da saúde e estratégia para se conseguir os direitos do cidadão. 


\section{REFERÊNCIAS}

ABJAUDE, S.A.R.; SILVA, N.R.; MARQUES, L.A.M.; RASCADO, R.R. Promoção da Saúde: orientação para alunos do ensino fundamental. Revista Conexão UEPG, v. 8, n. 2, p. 272-283, 2012. Disponível em: http://www.revistas2.uepg.br/index.php/conexao/article/viewFile/4573/3116 . Acesso em: 08 jan. 2013.

BALDONI, A.O.; PEREIRA, L.R.L. O impacto do envelhecimento populacional brasileiro para o sistema de saúde sob a óptica da farmacoepidemiologia: uma revisão narrativa. Revista de Ciências Farmacêuticas Básica e Aplicada, v. 32, n. 3, p. 313-321, 2011.Disponível em: http://serv-bib.fcfar.unesp.br/seer/index.php/ Cien Farm/article/viewFile/1505/1173 . Acesso em: 08 jan. 2013.

BIZELLI, M.H.S.S.; BARROZO, S.; TANAKA, J.S.; SANDRON, D.C. Informática para a terceira idade características de um curso bem sucedido. Revista Ciência em Extensão, São Paulo, v. 5, n. 2, p. 4-14, 2009. Disponível em: http://ojs.unesp.br/index.php/revista proex/article/view/43/269 Acesso em: 24 de jan. 2013.

BRASIL. Agência Nacional de Vigilância Sanitária. Gerência de Monitoramento e Fiscalização de Propaganda, de Publicidade, de Promoção e de Informação de Produtos Sujeitos a Vigilância Sanitária - GPROP. Projeto de educação e promoção da saúde no contexto escolar: o contributo da Agência Nacional de Vigilância Sanitária para o uso racional de medicamentos. Caderno de atividades/Agência Nacional de Vigilância Sanitária. Brasília: Anvisa, 1 ed., 30 p., 2007. Disponível em: http://www.anvisa. gov.br/propaganda/educacao saude/caderno atividades.pdf Acesso em: 25 de jan. 2013.

DOTTA, E.A.V.; POVA, A.P.M.; BRUNELLI, J.V.V.; MASCHETTO, A.L.R.; COSTA, M.A.M.; CAMPOS, J.A.D.B.; GARCIA, P.P.N.S. Avaliação de um curso sobre internet para terceira idade. Rev. Ciênc. Ext. v.8, n.3, p.23, 2012. Disponível em: http://ojs.unesp.br/index.php/revista_proex/article/view/673/737 Acesso: 24 jan. 2013

IBGE. Instituto Brasileiro de Geografia e Estatística. Séries estatísticas \& séries históricas. O Instituto. Rio de Janeiro; 2010a. Disponível em: http://www.ibge.gov.br/series estatisticas/ Acesso em: 25 jan. 2013.

IBGE. Instituto Brasileiro de Geografia e Estatística. Distribuição da população por sexo, segundo os grupos de idade Alfenas (MG) 2010b. Disponível em: http://www.censo2010.ibge.gov.br/sinopse/webservice/ frm piramide.php?codigo=310160 . Acesso em: 3 nov. 2012.

IBGE. Instituto Brasileiro de Geografia e Estatística. Censo 2010: País tem declínio de fecundidade e migração e aumentos na escolarização, ocupação e posse de bens duráveis. Comunicação Social dia 16 nov. 2011. Disponível em: http://www.ibge.gov.br/home/presidencia/noticias/noticia visualiza.php?id noticia=2018. Acesso em: 23 jan. 2013.

MARQUES, L.A.M. et al. Assistência à saúde do idoso integrante da UNATI (Universidade Aberta à Terceira Idade) da UNIFAL-MG. UDESC em Ação, v. 4, n. 1,10 p., 2010. Disponível em: http://www.revistas.udesc.br/ index.php/udescemacao/article/viewFile/1840/pdf 30. Acesso em: 24 jan. 2013.

MIRANDA, L.M.; FARIAS, S.F. Contributions from the internet for elderly people: a review of the literature. Interface - Comunic., Saúde, Educ., v.13, n.29, p.383-94, abr./jun. 2009. Disponível em: http://www.scielo. br/scielo.php?pid=S1414-32832009000200011\&script=sci_arttext Acesso: 24 jan. 2013.

OLIVEIRA, C.S.; COSTA, S.L.; COSTA, I.C.; LEMOS, C.E.S. Oficina de educação, memória, esquecimento 
e jogos lúdicos para a terceira idade. Revista Ciência em Extensão, v. 8, n. 1, p. 08-17, 2012. Disponível em: http://200.145.6.204/index.php/revista_proex/article/view/554/686 . Acesso em: 08 jan. 2013.

PINTO, M.M.M.; BARROS, V.B.; CARDAMONI, R.V.; MARCUSSI, F.L.; PINTO, T.J.A. Experiência de utilização de ferramentas lúdicas na abordagem. Revista Brasileira de Farmácia, v. 92, n. 1, p. 23-32. Disponível em: http://www.rbfarma.org.br/images/edicoes-em-pdf/2011/RBF R1 2011/rbf\%202011\%20 92\%201\%205.pdf. Acesso em: 25 jan. 2013., 2011.

PLUCENIO, R.M.; ASSIS, A.A.; ORLANDI, E.M. CASTELLANI, T.T. Atividades do Projeto "Educação em saúde como um exercício de inclusão social”: Ações em 2009. Extensio: Revista Eletrônica de Extensão, v. 7, n. 9, p. 12-23, 2010. Disponível em: http://www.periodicos.ufsc.br/index.php/extensio/article/view/18070221.2010v7n9p12/13050. Acesso em: 24 jan. 2013.

\section{AGRADECIMENTO}

Os autores agradecem a colaboração dos acadêmicos participantes do projeto UNAFAL; ao programa CEFAL pela administração do projeto; à ANVISA pelo material didático; ao Marcelo Armelin Pacheco coordenador do programa UNATI/UNIFAL-MG pela colaboração; e pelo apoio da Pró Reitoria de Extensão da UNIFAL-MG. 